\title{
Teaching Canadian Politics and Foreign Policy Onsite: Benefits and Challenges
}

James M. McCormick, Iowa State University

ABSTRACT This article discusses the benefits and challenges of offering an onsite seminar on Canadian politics and foreign policy and assesses how this format contributes to achieving the goals of the 2011 APSA report, Teaching Political Science in the 21st Century. First, the author describes the development and requirements of the College of Liberal Arts and Sciences Global Seminar series at Iowa State University, the structure of the seminar, and its operation in Ottawa. Second, several of the pedagogical and experiential benefits, as well as the challenges, for making the seminar successful are identified and discussed. Third, by weighing these benefits and challenges, the author concludes that such a seminar has the potential to serve as an effective model for increasing an understanding of Canadian politics among American students, as well as to meet several important recommendations for improving the teaching of political science today.

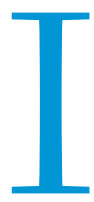
n 2009, the College of Liberal Arts and Sciences (LAS) at Iowa State University (ISU) initiated the LAS Global Seminar series. Under this initiative, faculty members were invited to develop a three-week intensive course at a studyabroad site where the local venue and expertise could be used to enhance the learning experience. In May 2011, I offered a "Canadian Politics and Foreign Policy" seminar for a group of Iowa State students to be held at the Institute of Canadian Studies at the University of Ottawa. As America's largest trading partner and key ally, as a parliamentary/federal governance system, and as a bilingual culture, Canada offers a wealth of interesting political characteristics to study. Furthermore-and remarkably-it is a country that few Americans know well.

In this article, I discuss the benefits and challenges of this type of course and venue, especially for American students; assess whether this seminar is a good model for American colleges and universities to follow for introducing students to Canadian politics; and evaluate how well such a seminar meets the teaching recommendations in the APSA's Political Science in the 21st Century (2011).

\section{LAS GLOBAL SEMINAR SERIES}

Study-abroad opportunities for students at ISU have a long history, but the development of a college-level program within LAS only began with this series. The model for this series was a workshop at the University of Minnesota, where an associate LAS dean learned about its program "and was encouraged to adapt their format for our own purposes" (Bratsch-Prince 2013). As a result, the Global Seminar series was initiated with a call for proposals in April 2009

James M. McCormick is a professor in the department of political science at Iowa State University.He can be reached at jmmcc@iastate.edu. for seminars to be held the following summer. This call noted that these seminars were to be "short-term, faculty-led summer studyabroad programs which are designed around a particular theme or topic" ("Call for Proposals, LAS Global Seminars" 2009). The length of the seminars was to be three to four weeks. The course subject matter was open, but the focus was "on topics of appeal to students in the social and natural sciences." The Global Seminar series had a number of specific requirements: 45 hours of onsite classroom instruction; several excursions at the study location to take advantage of the venue; limited enrollment to accommodate students and manage the seminar; application of normal academic standards; and an initial syllabus.

Faculty members who proposed a seminar went through a two-stage approval review process-first by a college committee and then by a university committee. When the approvals were obtained, the LAS faculty member could recruit students and more fully develop the curriculum. In a unique and useful feature of this series, the College of LAS offered to sponsor a site visit for the faculty member to make the necessary course, housing, and excursion arrangements and to contact local experts for possible participation.

\section{DEVELOPING THE "CANADIAN POLITICS AND FOREIGN POLICY" SEMINAR}

My seminar proposal called for students to examine the government, politics, and foreign policy of Canada from the unique vantage point of being located in Canada's capital city of Ottawa. The seminar would be held during a three-week period immediately following the end of the 2011 spring semester (May 10-27, 2011) and included a predeparture orientation at ISU in April 2011 to prepare the students for Ottawa. 
Because, in my experience, American students have limited knowledge of Canada and Canadian politics, the proposed course topics were broadly gauged: an overview of the historical development of Canada, the distinct bilingual political culture, the parliamentary governmental structure, and the principal political parties and interest groups. In the final section, the focus turned to Canadian foreign policy, albeit with a particular emphasis on US-Canadian ties. The proposal also called for visits to cultural sites, political institutions, and political-party headquarters in Ottawa. Furthermore, I identified several potential guest speakers (e.g., Jeffrey Simpson, The Globe and Mail political columnist; and Gerald Schmitz, an international affairs analyst with the Parliamentary Information and Research Service). Finally, the proposal called for using space at Carleton University to offer the seminar (with the University of Ottawa as a backup location).

I was fortunate to secure a site-visit grant from LAS so I could spend three days in Ottawa in October 2010 to solidify the course venue, excursions, and speakers. As a result, I decided to hold the seminar at the Institute of Canadian Studies at the University of Ottawa because that location allowed more immediate access to political institutions (e.g., Parliament and the Supreme Court) and was more economical than Carleton University. I also visited politicalparty headquarters, the US Embassy, and the Canadian Ministry of Foreign Affairs and International Trade to secure commitments to meet with the students. I also explored other venues (e.g., the Canadian Museum of Civilization and the National Gallery) to obtain information about tours for the students. The site visit was enormously helpful in arranging the details for the seminar.

In contrast to the success of the site visit, the recruitment of students proved to be a daunting and continuous task, right up to commencement of the seminar. According to the seminar procedures, the primary responsibility for recruitment rests with the faculty member. Three factors were key encumbrances in recruiting students. First, the availability of time to take the seminar was a problem. Students increasingly rely on summer work to support their education; hence, taking time off-even for a three-week period-can be difficult. Second, many students questioned the utility of Canada as a study-abroad venue, especially when other seminars were held in Europe and Asia. For many of the students, Canada was not viewed as a "foreign" experience. Third, cost was a crucial hindrance for enrolling in the seminar. Invariably, the their knowledge (McCormick and Chapelle 2011), which I reported the results to them. This exercise impressed the students with how much they needed to learn about Canada.

When we were in Ottawa, our procedure for the three-week period was to meet every weekday morning in a conference room in the Institute of Canadian Studies from 9 a.m. to about noon to discuss the assigned readings and course materials. On several afternoons, we traveled as a group to presentations and site visits. Although this schedule was not followed rigorously due to the timing of some presentations by our speakers, it allowed us to make good use of our time and to maximize exposure to Canadian politics and culture.

\section{BENEFITS OF THE LAS GLOBAL SEMINAR IN OTTAWA}

The "Canadian Politics and Foreign Policy" seminar provided several important pedagogical and experiential learning benefits for both the students and the instructor. At least three pedagogical benefits were immediately evident. First, the size and focus of the seminar facilitated an immediate immersion in Canadian politics and foreign policy. Because the class size was small and the daily interactions were intensive, the students quickly focused on various facets of Canadian culture and politics. A number of readings related to Canadian topics were assigned on a daily basis, and those readings were then reinforced by the instructor's and guests' presentations and discussions.

Second, the seminar was conducive for an "active-learning" environment. The course was structured in a way that students were required to prepare and present two in-class (i.e., PowerPoint) presentations on Canadian society (e.g., provincial differences) and politics (e.g., the differing Canadian political parties)-and submit papers from these presentations-and to write a short paper on a foreign-policy issue. Furthermore, all students were required to lead a discussion on one of the assigned readings from a fairly sophisticated collection of articles on Canadian politics. Third, the two short-answer essay tests were sufficiently comprehensive so that the students gained a broad appreciation of various elements of Canadian society and politics.

The experiential learning benefits accelerated the pedagogical benefits. First, the University of Ottawa is a bilingual university with about $40 \%$ of classes in English and the remaining in French. In this sense, the students were quickly immersed in a different

\section{In contrast to the success of the site visit, the recruitment of students proved to be a daunting and continuous task, right up to commencement of the seminar.}

first question asked in a presentation promoting the seminar was "What is the cost?" The question was difficult to answer precisely because, ultimately, the cost per student was tied to the number of participants. Initially, about twice as many students signed up for the seminar as those who actually completed the application and made the necessary financial commitment.

With a minimum number of students (i.e., seven) committed to the program, the initial orientation meeting was held on the ISU campus in late April 2011. At the meeting, the students were introduced to details of arriving in Ottawa, traveling to the University of Ottawa campus, and important information about the city. I presented an introductory lecture about Canada and Canadian politics and distributed a previously developed survey to assess cultural setting, and they recognized key differences (e.g., bilingualism) between Canada and the United States.

Second, the city and its environment had an immediate impact on the students. The magnificent and dominant parliamentary buildings in downtown Ottawa conveyed the differences in political institutions and structures between the two countries.

Third, Canadian political events contributed to highlighting differences with the United States. Entirely by happenstance, the seminar was held immediately after the Canadian national elections in which the Conservative Party gained a majority in Parliament, the New Democrats finished second, the Liberal Party lost a number of seats to finish third, and the Bloc Quebecois was reduced to two seats from Quebec. 
Fourth, the experience of hearing from local experts and key governmental and nongovernmental officials was the crucial component of the students' experiential learning in Ottawa. The meeting and discussion with Jeffrey Simpson were rated highest by the students. Simpson's broad knowledge of Canadian politics, his understanding of the United States, and his engaging style made his presentation of the Canadian election results mesmerizing and memorable for many of the students. A close second was our visit to Parliament and the briefing by Audrey O'Brien, Clerk of the House of Commons (the second-highest-ranking official). She was highly praised offers scholarships; however, students must meet the deadline, and the assistance is relatively modest. Alternate funding sources (e.g., departmental funding and foundation support) need to be developed.

A third pedagogical issue is related to the retention of interest in and knowledge about Canada after the seminar. From my limited experience with this LAS seminar, I was impressed by the students' interest in the various topics during the seminar. Of course, interest among some students was greater than for others, but the fact that we were "on the ground" in Ottawa and that events were occurring

\section{The larger issue for this compressed seminar is the students' degree of retention of knowledge about Canada, which is a lingering concern.}

by the students for her knowledge and a knack for the clever quip. Similarly, the visit to the American Embassy and the briefing (of almost two hours) by two US Foreign Service officers were important learning experiences, especially because none of the students had ever visited a US embassy. Finally, the Canadian Ministry of Foreign Affairs and International Trade also provided an interesting briefing and a view of a working foreign ministry.

Fifth, the opportunity to visit Parliament, the Supreme Court, Rideau Hall, the American Embassy, and the Canadian Foreign Ministry enhanced the classroom learning experience about these institutions. Furthermore, the opportunity to visit important cultural sites (e.g., the Canadian Museum of Civilization and the Canadian War Museum) provided a broader understanding of Canadian society-including a considerable amount of Canadian history that the students did not know. Indeed, side trips to Montreal and Toronto undoubtedly would have added value to the seminar, but timing and cost made them prohibitive.

In summary, the experiential side of the seminar is what made the seminar successful. I taught a similar course at ISU, but it did not generate the same interest or enthusiasm that occurred for these students.

\section{CHALLENGES OF THE LAS GLOBAL SEMINAR IN OTTAWA}

Although I believe that the seminar went well, it also made me aware of the challenges with this type of course and teaching political science in this way. Among the pedagogical challenges, the student recruitment/retention was the most difficult challenge for this type of short, concentrated course about Canada. As mentioned previously, students-or at least ISU students-were not convinced that Canada is a study-abroad venue. This may be more of an issue for those American colleges or universities that do not offer Canadian studies or politics courses. Nonetheless, it is an issue; therefore, certain actions (e.g., a course, a course module, or Canadian current events) are necessary to stimulate interest in Canada on campus-and eventually for an onsite seminar like the one described in this article.

A second challenge is the cost of the seminar. The price of the three-week seminar currently is about $\$ 3,000$ plus meals and entertainment, which is often an immediate obstacle for students. The College of LAS offered a $\$ 500$ scholarship to the first 10 students who signed up for one of the seminars, and that assistance obviously was helpful. Similarly, the University's Study Abroad Office daily sustained interest. The larger issue for this compressed seminar is the students' degree of retention of knowledge about Canada, which is a lingering concern.

The experiential learning challenges of the seminar focused on (1) availability of a venue and accommodation for the students, (2) availability and reliability of the speakers for the seminar, and (3) access to certain sites. Each concern resulted in different types of challenges for the seminar.

The venue for holding the seminar was a first major obstacle. As previously mentioned, I initially sought to hold the seminar at Carleton University, but the University of Ottawa and its Institute of Canadian Studies proved to be a better location in terms of access and cost. Another advantage, of course, was that the Institute was a focal point on campus for Canadian studies activities. Thus, it is important to strategically select the location to maximize the impact of the seminar on the students. Closely related to the venue issue was the housing question. The associated concerns, of course, include cost but also type of accommodation and period of time. The housing issues were mitigated somewhat because I had previously visited the Institute, was familiar with Ottawa, and had addressed some of these issues during the site visit.

A second challenge was the availability and reliability of local experts as speakers. Fortunately, I had established contacts during previous visits to Ottawa, which proved to be crucially important in identifying and obtaining speakers. I was especially grateful for the assistance in arranging our visit to Parliament and the two speakers there. Similarly, because I had hosted The Globe and Mail political columnist in Iowa, I was able to contact him directly and invite him to meet with the students. In turn, these contacts facilitated other speakers. Because of a previous meeting with a Foreign Service Officer from the US Embassy in Ottawa, I was able to arrange the briefing for the May seminar. Also, through previous contacts with officials in the foreign ministry, I could make arrangements for the briefing there. The important lesson is to have had previous onsite experience and to establish contacts who can assist in developing such a compressed seminar.

Other efforts in arranging speakers resulted in disappointment. Although I had contacted the principal political parties, only one representative of the Conservative Party met with the students. Despite several calls and e-mails, the other representatives failed to live up to their commitments. A similar difficulty arose with a political columnist who forgot about his commitment. The lesson learned from these experiences is the challenge of ensuring speakers, 
despite considerable advance efforts. It is wise to have a backup plan for speakers and other activities during the seminar.

A final challenge occurred when arranging appropriate and timely visits to political and cultural sites at the seminar location. Some difficulties that arise are unforeseen; others can be avoided. For instance, the class walked to Rideau Hall, the governor general's residence, only to find that it was temporarily closed for tours. Similarly, full access to the Supreme Court was prohibited at the time of our visit. Fortunately, however, an appeals court was in session, and we sat in on a case that was related to aboriginal rightsa topic that we had been discussing in the seminar. Finally, access about politics today. In October 2011, the APSA's Political Science in the 21st Century report provided a comprehensive analysis on the current teaching of political science, especially with regard to incorporation of diversity and inclusion in the process (Report of the Task Force on Political Science in the 21st Century 2011). At the end of the report, the task force made three general recommendations for addressing issues of diversity and inclusion in political science teaching: (1) political science needs to "critically analyze and interrogate issues of diversity, inclusiveness, and inequality"; (2) "there is a continuing need for the discipline to further internationalize the political science curriculum"; and (3) "there is a need to improve

\section{This type of seminar offers "students greater exposure to and knowledge about our world," "connects what is local and what is global," "encourage [s] and sustains [s] enthusiasm for the international dimensions of politics," and "emphasize [s] active learning that engages students to apply concepts learned in class to real-world situations" (Report of the Task Force on Political Science in the 21st Century 2011, 37).}

to the National Gallery and to the Canadian Museum of Civilization should be arranged at particular times for the best pricing. These political and cultural site issues are relatively minor; however, for a short seminar, they should be managed.

\section{AN APPROPRIATE MODEL FOR CANADIAN STUDIES AND TEACHING POLITICAL SCIENCE?}

Would this LAS Global Seminar series serve as a model for enhancing the study of Canadian politics? Would these types of seminars serve as a model for teaching political science today? The short response, I believe, is "yes" to both questions, although qualifications are necessary to answer them in the affirmative.

As shown elsewhere (McCormick and Chapelle 2011), Americansspecifically American college students-possess limited information about Canada. At one level, then, even a modest exposure to America's largest trading partner and closest neighbor advances the study of Canada. Still, there should be a healthy skepticism about the effectiveness of a single seminar and its impact because even after a course on Canadian politics, some American college students did not do any better in answering fundamental questions about Canada than those without such exposure (McCormick and Chapelle 2011).

Yet, this type of onsite seminar has the potential to spark more interest among students than a campus course on Canada in the middle of the United States. Arguably, there is potential for greater retention in that students can associate some of the information with their experiences in Ottawa. This type of comparison remains an important empirical question for measuring knowledge about Canada. Is the experiential seminar more effective than a semesterlong course on an American college campus in the level of knowledge that students receive and retain? My sense is that the seminar is more effective not only because of the experiential nature of the course but also because of the self-selection involved for the seminar participants. To summarize, this type of onsite seminar has the potential to be highly beneficial in advancing the study and knowledge of Canada.

From a political science disciplinary perspective, the LAS Global Seminar series approach also serves as a good model for teaching the textbooks used to instruct undergraduates" (Report of the Task Force on Political Science in the 21st Century 2011,36-7). Although a case could be made for the LAS Global Seminar in Ottawa addressing all three of these teaching needs, the report listed a number of specific actions that could be taken on the second recommendation The Ottawa seminar (and others like it) is most germane for improving the teaching of political science today. This type of seminar offers "students greater exposure to and knowledge about our world," "connects what is local and what is global," "encourage[s] and sustains [s] enthusiasm for the international dimensions of politics," and "emphasize[s] active learning that engages students to apply concepts learned in class to real-world situations" (Report of the Task Force on Political Science in the 21st Century 2011, 37). That is, students in the Ottawa seminar gained greater exposure to the world beyond Iowa and the United States; they were able to compare the local (i.e., Ames and Iowa) with the global (i.e., Ottawa and its environs); they gained some understanding of the global and international dimensions of politics; and they were engaged in active learning in both the classroom and Ottawa more generally.

In summary, the LAS Global Seminar series-and specifically the Ottawa experience-has the potential to serve as an important vehicle for stimulating and enlarging Canadian studies, but it also can provide an important model for improving the teaching of political science in the 21st century by quickly making coursework more diverse and international.

\section{R E F E R E N C E S}

Bratsch-Prince, Dawn. 2013. Personal e-mail communication, Associate Dean of the College of Liberal Arts and Sciences when the LAS Global Seminar series began, June 3 .

"Call for Proposals: LAS Global Seminars." 2009. College of Liberal Arts and Sciences, Iowa State University, January 27.

McCormick, James M., and Carol A. Chapelle. 2011. "Measuring Whether Canadian Studies Courses Make a Difference in Knowledge of Canada." The American Review of Canadian Studies 41 (December 2011): 451-67.

Report of the Task Force on Political Science in the 21st Century. 2011. Political Science in the 21st Century. Washington, DC: American Political Science Association, October. 